\title{
Pemetaan Status Kerusakan Tanah di Lahan Pertanian di Kecamatan Cepogo Kabupaten Boyolali
}

\section{Damage Status Mapping Soil in Agricultural Land in District Cepogo Boyolali}

\author{
Sumarno ${ }^{2)}$, Sri Hartati ${ }^{2)}$, Ratna C Hapsari ${ }^{1)}$
}

\begin{abstract}
Land used in agriculture plays an important role in supporting the production of biomass. Destruction of land for biomass production is changing the nature of the soil that exceeded the standard criteria of soil damage. Mapping of land degradation status is useful to know the condition of the soil and tillage correct action. This study was conducted using a survey in the Subdistrict Cepogo Regency Boyolali. Existing data will be scoring and macthing with standard criteria for biomass production ground damage that Government Regulation No. 150 of 2000 . Analysis of the data shows that there is no damage land area covering $744,1 \mathrm{Ha}(13,7 \%)$ and there are areas relatively lightly damaged by parameters of degradation status, namely the composition of the fraction covering 494,4 ha $(9,1 \%)$, the degree of release of water parameters covering 294,4 ha $(5,4 \%)$ and a combination of parameters fraction composition and the degree of release of water covering $1.813 \mathrm{Ha}(33,4 \%)$.
\end{abstract}

Keywords : soil damage, standard criteria, matching, map

\section{PENDAHULUAN}

Salah satu fungsi dari tanah yaitu sebagai media tumbuh tanaman untuk menghasilkan biomassa. Adanya kerusakan lahan pertanian akibat dari budidaya yang kurang tepat atau karena faktor dari luar akan mengakibatkan penurunan kualitas dari tanah itu sendiri (Sukisno et al. 2011). Kerusakan tanah untuk produksi biomassa adalah berubahnya sifat dasar tanah yang melampaui kriteria baku kerusakan tanah.

Dalam penentuan kerusakan tanah terdapat parameter-parameter yang mencakup sifat dasar tanah. Seperti yang disebutkan oleh Pemerintah RI (2000) antara lain $\mathrm{pH}$ tanah, redoks, jumlah total mikrobia, daya hantar listrik, komposisi fraksi, derajat pelulusan air, berat isi, porositas, kedalaman solum, kebatuan permukaan dan erosi.

Kecamatan Cepogo adalah salah satu kecamatan dari Sembilan belas kecamatan yang ada di kabupaten boyolali. Sebagian besar luas total kecamatan cepogo ialah lahan pertanian (BPS 2012). Dengan terpetakannya potensi dan status kerusakan tanah maka dapat diketahui tingkat kerusakan tanah yang ada dengan parameter penyebab kerusakannya. Selain itu dapat menentukan tindakan pengelolaan tanah yang sesuai sehingga kerusakan tanah dapat dicegah dan/atau diperbaiki.

\footnotetext{
1) Lecturer of Study Program of Agrotechnology, Faculty of Agriculture University of Sebelas Maret (UNS) In Surakarta.

2) Undergraduate Student of Study Program of Agrotechnology, Faculty of Agriculture University of Sebelas Maret (UNS) In Surakarta.

Contact author: ratnacahyaninghapsari@yahoo.com
}

\section{METODE PENELITIAN}

Percobaan ini dilaksanakan di Kecamatan Cepogo Kabupaten Boyolali dan analisis tanah di Laboratorium Pedologi dan Survei Tanah, Laboratorium Fisika dan Konservasi Tanah, Laboratorium Kimia dan Kesuburan Tanah serta Laboratorium Biologi dan Kesehatan Tanah Fakultas Pertanian Universitas Sebelas Maret Surakarta. Bahan yang digunakan yaitu peta curah hujan, peta jenis tanah, peta kontur dan peta penggunaan lahan (land use), sampel tanah terusik dan tidak terusik. Alat yang digunakan yaitu alat yang digunakan di lapang seperti GPS, kompas, meteran dll serta alat yang digunakan untuk analisis di laboratorium seperti analisis tekstur, berat volume dll.

Penelitian ini menggunakan metode survei yaitu penelitian dengan mengumpulkan dan mengamati kondisi di lapang, setelah itu dilakukan uji laboratorium. Diawali dengan penyiapan peta kerja. Penyusunan peta status kerusakan tanah dilakukan dengan metode matching dengan kriteria baku kerusakan tanah Peraturan Pemerintah Nomor 150 Tahun 2000. Selanjutnya dilakukan scoring dari hasil matching. Melakukan penjumlahan nilai skor dan pembuatan peta hasil.

\section{HASIL DAN PEMBAHASAN}

\section{Potensi Rusak Kecamatan Cepogo}

Menumpang susunkan (overlay) peta jenis tanah, peta curah hujan, peta kontur dan peta penggunaan lahan (land use) di Kecamatan Cepogo Kabupaten Boyolali akan didapatkan lokasi pengambilan titik sampel yang akan diambil. Pembuatan peta titik sampel dibuat dengan beberapa tahapan antara lain: (1) pembuatan peta wilayah efektif, (2) kemudian dilakukan penskoringan potensi kerusakan lahan pada peta tematik, (3) overlay peta tematik akan 
dihasilkan satuan peta lahan/SPL dan titik sampel, (4) pembuatan peta potensi rusak.

Peta wilayah efektif

Peta wilayah efektif ialah peta yang berisi tentang wilayah atau daerah yang termasuk ke dalam wilayah yang memiliki kemampuan untuk menghasilkan biomassa pertanian yang ada di Kecamatan Cepogo Kabupaten Boyolali seperti daerah pertanian dan perkebunan. Luas wilayah yang termasuk ke dalam wilayah efektif 3.345,9 Ha sedang untuk wilayah yang bukan termasuk ke dalam wilayah efektif yaitu $2.077,5$ $\mathrm{Ha}$.

\section{Penskoringan Potensi Kerusakan Tanah}

Nilai skoring potensi kerusakan tanah didapatkan dari hasil perkalian antara nilai rating (nilai potensi masing-masing unsur peta tematik terhadap kerusakan tanah dengan nilai bobot masing-masing peta tematik yaitu peta tanah, peta kontur, peta curah hujan, peta penggunaan lahan). Nilai rating ditetapkan berkisar 1 sampai 5 , sementara nilai bobot didasarkan kepada penilaian potensi kerusakan tanah. Semakin tinggi nilai skoring pembobotan yang didapat, semakin tinggi pula potensi wilayah tersebut mengalami kerusakan tanah. Dari hasil penskoringan didapatkan bahwa untuk potensi kerusakan tanah rendah berada di SPL 1, untuk rusak sedang berada di SPL 2,3,4,5,6,8 dan 9. Untuk rusak tinggi berada di SPL 7,10 dan 11. Skoring setiap peta tematik dapat dilihat pada Tabel 1.

\section{Overlay Peta Tematik}

Setelah didapatkan areal kerja efektif dan nilai skor dari masing-masing peta tematik, maka selanjutnya dilakukan overlay peta tematik. Hasil dari overlay yang ada akan menghasilkan poligon-poligon baru dengan atribut kondisi lahan sesuai dengan peta tematik yang digunakan. Dari hasil overlay didapatkan 11 satuan peta lahan/SPL. Sehingga akan didapatkan 11 titik pengambilan sampel.

\section{Peta Potensi Rusak Kecamatan Cepogo}

Peta potensi rusak menjelaskan tentang luas wilayah penelitian yang dihasilkan dari skor pembobotan potensi kerusakan tanah setiap peta tematik yang ada. Terdapat 3 kelas kerusakan tanah yaitu PR II (kerusakan rendah), PR III (kerusakan sedang) dan PR IV (kerusakan tinggi). Luas wilayah yang termasuk ke dalam PR II (kerusakan rendah) yaitu 148,3 ha dengan persentase $2,2 \%$. Untuk luas wilayah yang termasuk dalam PR III (kerusakan sedang) yaitu 2.917,4 Ha dengan persentase 53,8\%. Untuk luas wilayah yang termasuk ke dalam PR IV (kerusakan tinggi) yaitu seluas 280,2 Ha dengan persentase $5,2 \%$. Sedangkan untuk sisa wilayah sebanyak 2.077,5 Ha dengan persentase 38,8\% masuk kedalam BWE (bukan wilayah efektif).

\section{Status Kerusakan Tanah untuk Produksi Biomassa}

\section{Penentuan Status kerusakan Tanah}

Penentuan status kerusakan tanah terbagi menjadi dua tahap evaluasi yaitu: matching atau membandingkan data parameter hasil pengamatan dengan kriteria baku kerusakan tanah untuk produksi biomassa yang telah ditentukan. Tahap berikutnya yaitu scoring, yaitu menghitung frekuensi relative tanah yang tergolong rusak sesuai dengan kriteria baku yang sudah ada.

Kesebelas SPL yang ada memiliki ketinggian yang bermacam-macam namun berada diatas 500 meter diatas permukaan laut. Penggunaan lahannya tegalan dan kebun campuran, namun sebagian besar lahan digunakan untuk tegalan. Curah hujan yang ada di Kecamatan Cepogo 2000-3000 untuk keseluruhan SPL yang ada. Kemiringan lereng beraneka ragam mulai dari $4 \%$ hingga $41 \%$. Konservasi tanah yang ada yaitu dengan dibuat teras tradisional dan teras bangku.

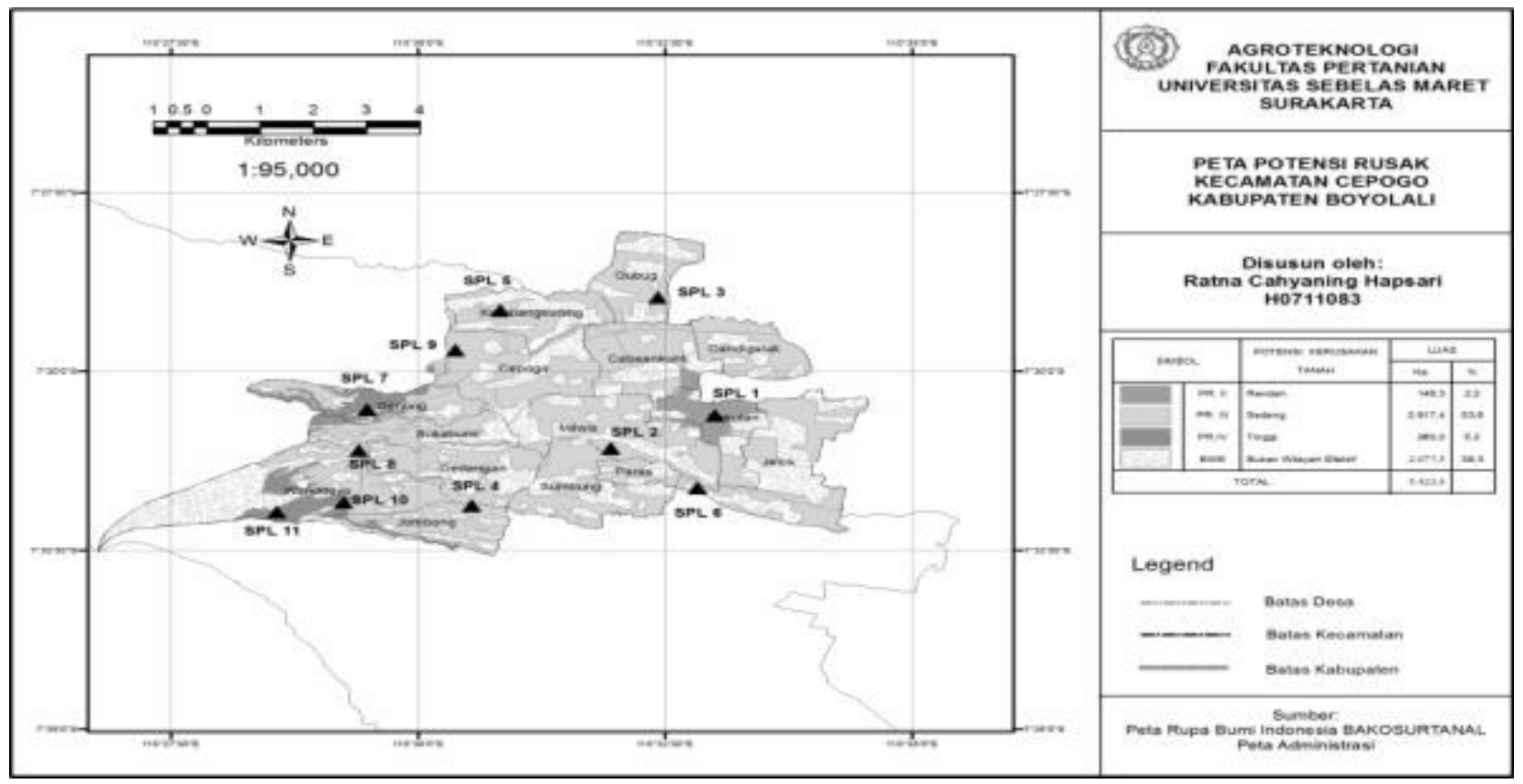

Gambar 1. Peta Potensi Rusak Kecamatan Cepogo 
Agrosains 17(1): 21-26, 2015; ISSN: 1411-5786

Tabel 1. Karakteristik lapangan Kecamatan Cepogo

\begin{tabular}{|c|c|c|c|c|c|c|c|c|c|}
\hline SPL & $\begin{array}{l}\text { Dusun/ } \\
\text { Desa }\end{array}$ & Elevasi & $\begin{array}{l}\text { Penggunaan } \\
\text { lahan }\end{array}$ & Vegetasi & $\begin{array}{l}\text { Curah } \\
\text { hujan }\end{array}$ & $\begin{array}{l}\text { Bahan } \\
\text { induk }\end{array}$ & $\begin{array}{l}\text { Kemiringan } \\
\text { lereng (\%) }\end{array}$ & $\begin{array}{l}\text { Panjang } \\
\text { lereng }(\mathrm{m})\end{array}$ & $\begin{array}{l}\text { Tindakan } \\
\text { konservasi }\end{array}$ \\
\hline 1 & Bakulan & 696 & $\begin{array}{l}\text { Kebun } \\
\text { campuran }\end{array}$ & $\begin{array}{l}\text { Cabai, } \\
\text { papaya, } \\
\text { durian, } \\
\text { nangka,kela } \\
\text { pa, sengon }\end{array}$ & $\begin{array}{l}2000- \\
3000\end{array}$ & Vulkanik & 4 & 16 & $\begin{array}{l}\text { Teras } \\
\text { tradisional }\end{array}$ \\
\hline 2 & Mliwis & 831 & Tegalan & $\begin{array}{l}\text { Cabai, } \\
\text { ketela, } \\
\text { rumput gajah }\end{array}$ & $\begin{array}{l}2000- \\
3000\end{array}$ & Vulkanik & 10 & 15 & $\begin{array}{l}\text { Teras } \\
\text { bangku }\end{array}$ \\
\hline 3 & Gubug & 706 & Tegalan & $\begin{array}{l}\text { Cabai, } \\
\text { sengon, } \\
\text { pisang, } \\
\text { bambu, } \\
\text { rumput } \\
\text { gajah, } \\
\text { kelapa }\end{array}$ & $\begin{array}{l}2000- \\
3000\end{array}$ & Vulkanik & 5 & 15 & $\begin{array}{l}\text { Teras } \\
\text { tradisional }\end{array}$ \\
\hline 4 & Jombong & 1033 & Tegalan & $\begin{array}{l}\text { Cabai, ketela } \\
\text { pohon, } \\
\text { tembakau, } \\
\text { timun, sawi } \\
\text { putih, kapri }\end{array}$ & $\begin{array}{l}2000- \\
3000\end{array}$ & Vulkanik & 11 & 19 & $\begin{array}{l}\text { Teras } \\
\text { bangku }\end{array}$ \\
\hline 5 & $\begin{array}{l}\text { Kembang } \\
\text { Kuning }\end{array}$ & 907 & Tegalan & $\begin{array}{l}\text { Tembakau, } \\
\text { kacang } \\
\text { tanah, } \\
\text { jagung, } \\
\text { ketela } \\
\text { pohon, } \\
\text { wortel, } \\
\text { kacang } \\
\text { panjang }\end{array}$ & $\begin{array}{l}2000- \\
3000\end{array}$ & Vulkanik & 16 & 16 & $\begin{array}{l}\text { Teras } \\
\text { tradisional }\end{array}$ \\
\hline 6 & Jelok & 704 & Tegalan & $\begin{array}{l}\text { Cabai, mindi, } \\
\text { pisang, } \\
\text { singkong, } \\
\text { rumput gajah }\end{array}$ & $\begin{array}{l}2000- \\
3000\end{array}$ & Vulkanik & 10 & 8 & $\begin{array}{l}\text { Tanpa } \\
\text { tindakan } \\
\text { konservasi }\end{array}$ \\
\hline 7 & Genting & 1255 & Tegalan & $\begin{array}{l}\text { Bawang } \\
\text { merah, } \\
\text { tembakau, } \\
\text { wortel, mindi }\end{array}$ & $\begin{array}{l}2000- \\
3000\end{array}$ & Vulkanik & 18 & 12 & $\begin{array}{l}\text { Teras } \\
\text { tradisional }\end{array}$ \\
\hline 8 & $\begin{array}{l}\text { Wonodoy } \\
\text { o }\end{array}$ & 1275 & Tegalan & $\begin{array}{l}\text { Bawang } \\
\text { merah, adas, } \\
\text { tembakau, } \\
\text { rumput gajah }\end{array}$ & $\begin{array}{l}2000- \\
3000\end{array}$ & Vulkanik & 13 & 16 & $\begin{array}{l}\text { Teras } \\
\text { tradisional }\end{array}$ \\
\hline 9 & Cepogo & 1031 & Tegalan & $\begin{array}{l}\text { Cabai, } \\
\text { bawang } \\
\text { merah, } \\
\text { singkong, } \\
\text { pisang, } \\
\text { mindi }\end{array}$ & $\begin{array}{l}2000- \\
3000\end{array}$ & Vulkanik & 12 & 16 & $\begin{array}{l}\text { Teras } \\
\text { bangku }\end{array}$ \\
\hline 10 & $\begin{array}{l}\text { Wonodoy } \\
\text { o }\end{array}$ & 1315 & Tegalan & $\begin{array}{l}\text { Bawang } \\
\text { merah, } \\
\text { tembakau, } \\
\text { cabai, sawi } \\
\text { hijau }\end{array}$ & $\begin{array}{l}2000- \\
3000\end{array}$ & Vulkanik & 25 & 8 & $\begin{array}{l}\text { Teras } \\
\text { bangku }\end{array}$ \\
\hline 11 & $\begin{array}{l}\text { Wonodoy } \\
\text { o }\end{array}$ & 1573 & Tegalan & $\begin{array}{l}\text { Bawang } \\
\text { merah, } \\
\text { tembakau, } \\
\text { kapri }\end{array}$ & $\begin{array}{l}2000- \\
3000\end{array}$ & Vulkanik & 41 & 7 & $\begin{array}{l}\text { Teras } \\
\text { tradisional }\end{array}$ \\
\hline
\end{tabular}

Sumber: Analisis lapang. 
Agrosains 17(1): 21-26, 2015; ISSN: 1411-5786

Tabel 2. Matching nilai parameter kerusakan tanah tiap satuan peta lahan Kecamatan Cepogo

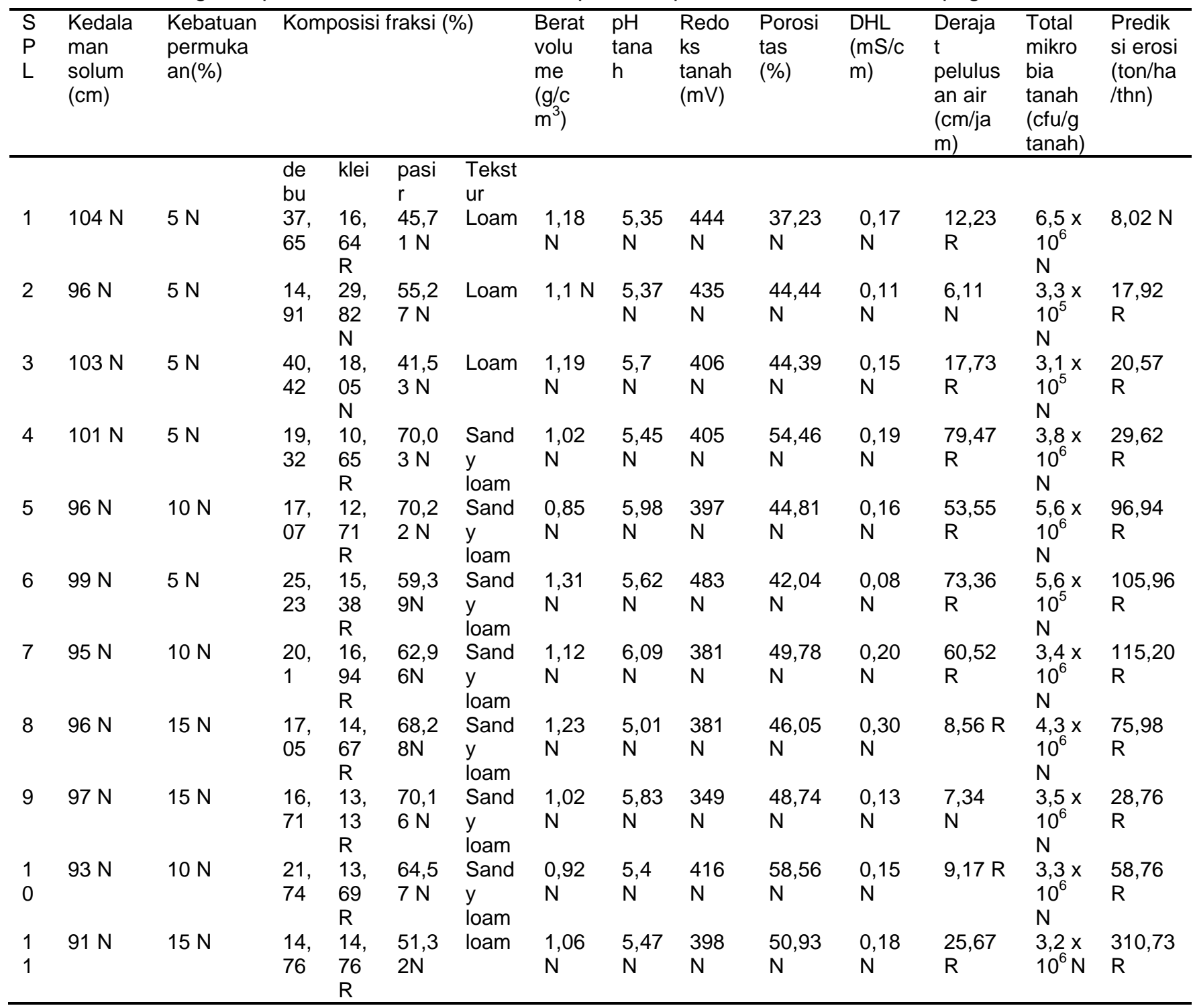

Sumber: Analisis laboratorium.

Keterangan: R: rusak; N: tidak rusak.

Variabel kerusakan tanah yang digunakan dalam penelitian ini ialah variabel dari parameter kerusakan tanah untuk produksi biomassa berdasarkan PP No.150 (2000) yaitu antara lain ketebalan solum, persentase batuan permukaan, tekstur tanah, berat volume tanah, porositas, permeabilitas, $\mathrm{pH}$, daya hantar listrik (DHL), redoks, jumlah mikrobia dan erosi tanah.

\section{Matching Data dengan Kriteria Baku}

Pembuatan peta status kerusakan tanah diawali dengan matching data yang ada dengan kriteria baku kerusakan tanah. Didapatkan bahwa untuk jenis tanah yang ada di kesebelas SPL ini antara lain Andisol, Kompleks Regosol dan Litosol serta Latosol. Sedangkan teksturnya termasuk loam dan sandy loam. Hampir seluruh SPL memilik parameter yang tergolong rusak sama yaitu komposisi fraksi, permeabilitas dan erosi.

Ditinjau dari jenis tanah yang ada, menurut Brady (1984) tanah Regosol memiliki nilai permeabilitas dan infiltrasi yang cepat hingga sangat cepat serta daya tahan terhadap airnya rendah. Hal ini dikarenakan kemantapan agregatnya pasir kurang stabil dan sering memiliki struktur yang lepas. Diantara pertikel yang ada terdapat daya ikat dan bahan organik yang rendah sehingga unsur haranya juga rendah. Soepardi dan Goeswono (1983) berpendapat bahwa tanah Regosol bertekstur kasar, berbahan organik dan $\mathrm{N}$ yang rendah hal ini disebabkan karena kadar air yang rendah.

Latosol merupakan tanah bersolum dalam yang mengalami pencucian dan pelapukan lanjut. Ciri morfologi umum tanah Latosol yaitu bertekstur lempung sampai geluh, strukturnya remah sampai gumpal lemah dan konsistensi gembur (Munir 1996). Menurut Abdullah (1996) dalam pemetaan tanah, diusahakan agar dalam satu satuan peta tanah hanya didapatkan satu jenis tanah, tetapi di beberapa tempat hal tersebut sering sulit diterapkan karena beragamnya sifat bahan induk, topografi atau faktor pembentuk tanah yang lain. Kompleks yang dimaksut ialah bahwa dalam satu peta tanah didalamnya ditemukan dua atau lebih jenis tanah utama, namun 
masing-masing jenis tanah utama tersebut tidak dapat dipisahkan menjadi satuan peta tanah sendiri. Di SPL ini terdapat kompleks antara Regosol dan Litosol.

Tanah Andisol memiliki kandungan bahan organik yang tinggi, bobot isi rendah, daya menahan air tinggi, total porositas tinggi. Tanah Andisol memiliki ciri yaitu berwarna gelap akibat dari tingginya kadar bahan organik, gembur, terasa berminyak, $\mathrm{pH}$ berkisar antara 5-6,5 (Tan 1991). Tanah ini termasuk tanah yang subur dan produktif. Tanah ini memiliki berat volume rendah, permeabilitas tinggi, terasa berminyak dengan kapasitas menyimpan air yang besar tetapi fiksasi fosfat tinggi.

Ditinjau dari kemiringan lereng dan panjang lereng, suatu tanah yang mempunyai kepekaan rendah mungkin akan mengalami erosi yang berat jika tanah tersebut terletak pada lereng yang curam dan panjang serta curah hujan dengan intensitas yang selalu tinggi. Sebaliknya juga jika tanah yang memiliki kepekaan erosi tinggi kemungkinan akan mengalami erosi yang ringan jika terdapat pada lereng yang landai dengan tanaman penutup tanah yang baik dan hujan yang tidak berintensitas tinggi.

Menurut Suripin (2001) bentuk struktur tanah yang membulat seperti granuler, remah, dan gumpal membulat akan menghasilkan tanah dengan porositas tinggi sehingga air mudah meresap ke dalan tanah dan aliran permukaan menjadi kecil. Untuk struktur tanah yang tidak mantap akan mudah hancur menjadi butiran halus jika terkena pukulan air hujan yang akhirnya menyumbat pori-pori tanah, akibatnya aliran permukaan meningkat dan erosi juga meningkat.

Dilihat dari tindakan konservasi yang ada, kerusakan dapat disebabkan karena kurangnya kerapatan jarak tanam serta adanya konservasi tanah yang kurang tepat. Seperti contoh pada SPL 11 dengan kemiringan lereng $41 \%$ hanya diberi konservasi tanah dengan teras tradisional seharusnya dibuat konservasi yang lebih sesuai agar tingkat kerusakan yang ada bisa dikurangi. Menurut Arsyad (2010) konservasi tanah ialah upaya menempatkan setiap bidang tanah pada cara penggunaan yang sesuai dengan kemampuan tanah dan memperlakukan sesuai dengan syarat-syarat yang diperlukan agar tidak terjadi kerusakan tanah serta dapat memiliki tingkat produktivitas yang baik.

\section{Skoring frekuensi relatif}

Setelah dilakukan pembandingan data yang selanjutnya dilakukan tahap penskoringan frekuensi relative setiap parameter yang ada. Kemudian dilakukan penjumlahan skoring yang ada. Hasil penskoringan dari setiap parameter kerusakan tanah untuk biomassa didapatkan dari sebelas lokasi penelitian didapatkan total skor 7. Berdasarkan Pemerintah RI (2000) skor kerusakan tanah untuk lahan kering antara 1-14 tergolong ke dalam rusak ringan. Didapatkan bahwa terdapat 2 status kerusakan yaitu status tidak rusak dan status rusak ringan.

Dilihat dari parameter kerusakan yang ada (komposisi fraksi, derajat pelulusan air dan erosi) maka dapat disimpulkan untuk memperbaiki sifat tanah yang ada dapat diberikan bahan organik. Karena tanah yang sebagian besar persentase fraksinya pasir diperlukan adanya penambahan klei untuk mempermudah pengelolaannya. Selain sebagai unsur hara, bahan organik juga mampu memperbaiki struktur tanah sehingga tanah akan cukup kuat dalam menahan air. Sehingga dapat meningkatkan kesuburan tanah yang ada.

Seperti yang diungkapkan oleh Stevenson (1982) bahan organik berperan dalam pembentukan agregat tanah yaitu dapat merekatkan antar partikel sehingga penting dalam pembentukan partikel tanah. Pada tanah pasiran bahan organik dapat mengubah struktur dari berbutir agregat tunggal menjadi gumpal. Sehingga dapat merubah derajat struktur menjadi baik atau remah dan ukuran agregat lebih besar.

Selain itu bahan organik mampu mempengaruhi kapasitas pertukaran kation dan anion, $\mathrm{pH}$ tanah dan daya sangga tanah. Bahan organik akan meningkatkan muatan negatif sehingga mampu meningkatkan kapasitas pertukaran kation.

Tabel 3. Skor kerusakan tanah berdasarkan frekuensi relatif dari berbagai parameter kerusakan tanah

\begin{tabular}{lllll}
\hline No Sampel & Parameter & $\begin{array}{l}\text { Frekuensi relative } \\
\text { tanah rusak (\%) }\end{array}$ & Skor & Status kerusakan tanah \\
\hline 1 & Ketebalan solum & 0 & 0 & Tidak rusak \\
2 & Kebatuan permukaan & 0 & 0 & Tidak rusak \\
3 & Komposisi fraksi kasar & 72,72 & 3 & Rusak berat \\
4 & Berat volume & 0 & 0 & Tidak rusak \\
5 & Porositas total & 0 & 0 & Tidak rusak \\
6 & Derajat pelulusan air & 81,81 & 4 & Rusak sangat berat \\
7 & pH H $\mathrm{H}_{2} \mathrm{O}: 2,5$ & 0 & 0 & Tidak rusak \\
8 & DHL & 0 & 0 & Tidak rusak \\
9 & Redoks & 0 & 0 & Tidak rusak \\
10 & Jumlah mikrobia & 0 & 0 & Tidak rusak \\
& Jumlah skor & & $7^{*}$ & \\
\hline
\end{tabular}

Sumber: Hasil laboratorium.

Keterangan: Jumlah skor 7 menandakan bahwa termasuk ke dalam status kerusakan tanah ringan. 


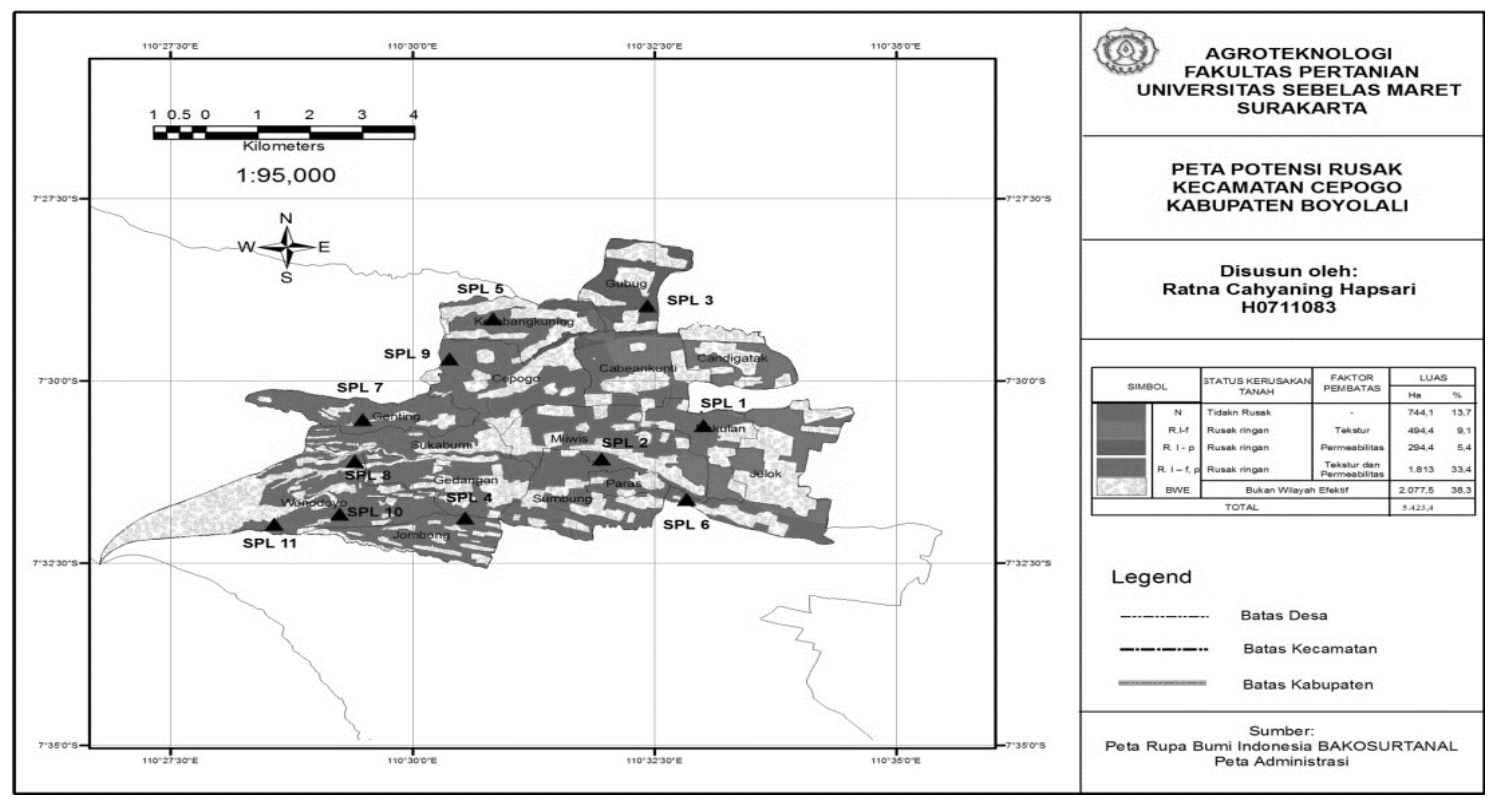

Gambar 2. Peta Status Rusak Kecamatan Cepogo

Didapatkan 2 status kerusakan yaitu status tidak rusak dan status rusak ringan. Untuk status tidak rusak dengan luas $744,1 \mathrm{Ha}$ atau sebesar $13,7 \%$, sedang status rusak ringan terbagi menjadi 3 kelas rusak ringan yaiu status rusak ringan dengan faktor penghambat komposisi fraksi seluas $494,4 \mathrm{Ha}$ atau sebesar $9,1 \%$, status rusak ringan dengan faktor penghambat derajat pelulusan air dengan luas 294,4 $\mathrm{Ha}$ atau sebesar $5,4 \%$, status rusak ringan dengan faktor penghambat komposisi fraksi dan derajat pelulusan air dengan luas $1.813 \mathrm{Ha}$ atau sebesar $33,4 \%$.

\section{KESIMPULAN DAN SARAN}

\section{Kesimpulan}

Kesimpulan yang didapat dari penelitian ini ialah:

1. Hasil penelitian ini termasuk didapatkan bahwa Kecamatan Cepogo Kabupaten Boyolali memiliki dua status yaitu yang tergolong tidak rusak dengan luas 744,1 Ha meliputi SPL dan tergolong rusak dengan luas total $2.601,8 \mathrm{Ha}$.

2. Parameter yang menjadi pembatas dan penyumbang skor kerusakan tanah dari status rusak ringan yaitu komposisi fraksi (R.I-f) seluas 494,4 Ha (9,1\%), derajat pelulusan air (R.I-p) seluas $294,4 \mathrm{Ha}(5,4 \%)$ dan gabungan antara komposisi fraksi dan derajat pelulusan air (R.I-f,p) seluas $1.813 \mathrm{Ha}(33,4 \%)$.

\section{Saran}

Saran yang bisa diberikan untuk penelitian ini yaitu perlunya analisis tentang jenis mikrobia yang dibiakkan agar dapat mengetahui mikroba apa yang ada didalam tanah tersebut guna mengetahui apakah termasuk mikroba menguntungkan atau merugikan.

\section{DAFTAR PUSTAKA}

Abdullah TS. 1996. Survey tanah dan evaluas lahan. Jakarta (ID): Gramedia.

Arsyad S. 2010. Konservasi tanah dan air. Bogor (ID): IPB Press Edisi kedua cetakan kedua.
Badan Pusat Statistic Kecamatan Cepogo. 2012. Cepogo dalam angka. Cepogo Kabupaten Boyolali.

Brady B. 1982. Ilmu tanah. Soegirman (Translator). Jakarta (ID): Bhratara Karya Aksara. Translating From: Soil Sciene.

Munir M. 1996. Tanah-tanah utama Indonesia karakteristik, klasifikasi dan pemanfaatannya. Malang (ID): Pustaka Jaya.

Peraturan Pemerintah Lingkungan Hidup No 7 Tahun. 2006. Tata Cara Pengukuran Kriteria Baku Kerusakan Tanah Untuk Produksi Biomassa.

Peraturan Pemerintah Lingkungan Hidup No 150 Tahun. 2000. Pengendalian kerusakan tanah untuk produksi biomassa.

Supardi, Goeswono. 1983. Sifat dan ciri tanah. Bogor (ID): Institut Pertanian Bogor.

Suripin 2001. Pelestarian sumberdaya tanah dan air. Yogyakarta (ID): Andi.

Stevenson FT. 1982. Humus chemistry. New York (NY): John Wiley and Sons.

Tan KH. 1991. Dasar-dasar kimia tanah. Gajahmada University Press.

Winarso S. 2005. Kesuburan tanah dasar kesehatan dan kualitas tanah. Yogyakarta (ID): Gava Media. 